\title{
The incidence of respiratory symptoms and sensitisation in baker apprentices
}

\author{
T. Skjold*, R. Dahl*, B. Juhl ${ }^{\#}$ and T. Sigsgaard ${ }^{\top}$
}

ABSTRACT: The aim of the current study was to describe the incidence of respiratory symptoms and allergic sensitisation and the sequence of events leading to respiratory symptoms among Danish baker apprentices (BA). A total of 114 BA were surveyed over a 20-month period. Questionnaires were completed along with spirometric analysis and skin-prick tests to common and work-related allergens. Bronchial hyperresponsiveness (BHR) was determined at baseline and at the end of the follow-up period.

The incidences of work-related rhinitis and asthma-like symptoms were 22.1 and 10.0 cases 100 person-yrs ${ }^{-1}$, respectively. At 20 months the cumulative incidence proportion was 40.2 and $20.5 \%$ for rhinitis and asthma-like symptoms, respectively. The cumulative incidence of occupational sensitisation was $6.1 \%$.

An increased risk of asthma-like symptoms was found in both atopic subjects and in females. In the BA with new onset respiratory symptoms, an increase in BHR from baseline was observed. Forced expiratory volume in one second and forced vital capacity did not change during the follow-up period. No relationship was observed between new sensitisation and new symptoms.

In conclusion rhinitis- and asthma-like symptoms were found to develop commonly in Danish baker apprentices. The mechanism by which symptoms arose was perceived to reflect the development of an inflammation rather than the production of a specific immunoglobulin $E$ pathway, as sensitisation to occupational allergens was rarely observed. Hence, respiratory symptoms and allergy may develop through separate pathways.

KEYWORDS: Atopy, bronchial asthma, bronchial hyperresponsiveness, incidence, occupational disease, rhinitis

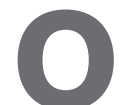

ccupational exposures are important contributing factors in $5-19 \%$ of all cases of adult asthma [1]. Bakers have the highest incidence of occupational asthma. The national yearly incidence rates vary between 28.5 cases $^{\circ} 100$ person-yrs ${ }^{-1}$ [2] in the UK and 400 cases $\cdot 100$ person-yrs ${ }^{-1}$ [3] in Finland. This is probably due to differing registration practices and diagnostic procedures [4].

The prevalence and the risk factor for baker's asthma and rhinitis have mainly been evaluated in cross-sectional studies. Reported prevalence of asthma and rhinitis has been in the range of 4-14 and 14-29\%, respectively [5]. In a Danish crosssectional study the prevalence of baker's asthma was $5 \%$ and the prevalence of sneezing, runny nose and blockage of the nose was 39.5, 27.2 and $28.6 \%$, respectively [6]. None of the studies distinguished between work-aggravated asthma and rhinitis and new-onset asthma and rhinitis. The aim of the present study was to investigate this in more detail.

The primary allergens in bakeries are components of wheat- and rye-flour proteins including $\alpha$-amylase $[7,8]$. In a recent study, $\sim 60 \%$ of bakers seeking compensation for work-related respiratory symptoms were sensitised to wheat or rye flour and $22 \%$ had immunoglobulin (Ig)E antibodies to $\alpha$-amylase [9].

The relationship between exposure to allergens, sensitisation and symptoms is not clear. In one cross-sectional study, a close relationship was found between respiratory symptoms and sensitisation [8]. However, other studies have shown that a high proportion of work-related symptoms response to a dusty environment [10-15].

The "allergic march" hypothesis originates from cross-sectional studies. However, a recent well performed longitudinal study of bakers apprentices (BA) [16] failed to confirm the allergic march hypothesis.

With this background information, the present authors performed a longitudinal investigation in order to study the sequence of events leading to symptoms, as well as incidences of respiratory symptoms and sensitisation in Danish BA. have no allergic basis and are the result of a direct
AFFILIATIONS

*Dept of Respiratory Diseases, Aarhus University Hospital,

\#Dept of Respiratory Medicine, Aarhus University Hospital, Aalborg Hospital, and

"Dept of Environmental and Occupational Medicine, Institute of Public Health, Aarhus University Denmark, Aarhus C, Denmark.

\section{CORRESPONDENCE}

T. Skjold

Dept of Respiratory Medicine

Aarhus University Hospital

Noerrebrogade 44

8000 Aarhus C

Denmark

Fax: 4589492110

E-mail: tina.skjold@dadlnet.dk

Received:

August 182007

Accepted after revision:

March 112008

STATEMENT OF INTEREST

None declared. 


\section{MATERIAL AND METHODS Subjects}

The study design has been previously described by SKJOLD et al. [17]. In brief, 347 BA were invited to participate in a study over a 2-yr period. Of these, 197 accepted and 187 participated in the first examination with 114 (61\%) undergoing a minimum of one follow-up visit. The initial drop-out rate was mainly related to the inability of the BA to find a baker who would accept them for vocational training.

A methacholine challenge test was performed upon entering and leaving the study. At 4-month intervals spirometry analysis, skin-prick test (SPT) and symptoms were assessed and recorded.

The first visit (inclusion) was carried out during the second school period, when exposure was minimal. The second visit (the first follow-up visit) occurred 4 months after occupational exposure. Seven of the included BA had been exposed for $>6$ months prior to study recruitment.

After the first visit, the current authors had only a modest drop-out rate and $87 \mathrm{BA}$ attended all follow-up visits up to 20 months (table 1).

The protocol was accepted by the Scientific Ethics Committee of Aarhus (Viborg, Denmark). All subjects gave written informed consent prior to study participation.

\section{Questionnaire}

A modification of the European Community Respiratory Health Survey (ECRHS) questionnaire was administered by a physician [18]. The BA were asked about the presence and date of onset for the following symptoms that were not related to airways infections during the preceding period: asthma-like symptoms and rhinitis- and/or eye-symptoms. A smoking history was also obtained. The subjects were also asked if their symptoms were aggravated during work. New respiratory symptoms were registered according to the ECRHS protocol [19].

\section{Skin-prick tests}

SPT were performed using a standard procedure and recorded after15 min [20]. A positive reaction was recorded when the mean of the longest diameter and the mid-point orthogonal diameter of the wheal was $\geqslant 3 \mathrm{~mm}$ [20]. Diluent was used as a negative control and histamine at a concentration of $10 \mathrm{mg} \cdot \mathrm{mL}^{-1}$ was used as a positive control.

Common inhalant allergens (Soluprick ALK; ALK-Abelló ${ }^{\circledR}$, Hørsholm, Denmark) used were: birch (Betula verruca), grass (Phleum pratense), mugwort (Artemisia vulgaris), horse, cat, dog, two house dust mites $\left(\operatorname{Der} P_{1}, \operatorname{Der} F_{1}\right)$, Alternaria alternate and Cladosporium herbarum. The occupational allergens in bakeries were in weight per volume: Acarus siro 1:100, Lepidoglyphus destructor 1:100, Aspergillus fumigatus 1:20, wheat 1:20, rye 1:20, oat 1:20, barley 1:20, and mouse 1:100. Extracts reconstituted in the Dept of Respiratory Medicine (Aarhus University Hospital, Aarhus, Denmark) were: Fungamyl ${ }_{\circledR}(\alpha$-amylase; Novo Nordisk, Bagsvaerd, Denmark) $4 \mathrm{mg} \cdot \mathrm{mL}^{-1}$, Novamyl ${ }_{\circledR}$ (Maltogenic amylase; Novo Nordisk) $4 \mathrm{mg} \cdot \mathrm{mL}^{-1}$, Pentopan ${ }^{\mathrm{TM}} 500$.

(Hemicellulase; Novo Nordisk) $4 \mathrm{mg} \cdot \mathrm{mL}^{-1}$, cockroach (Blatella germanica; ALK-Abelló) $4 \mathrm{mg} \cdot \mathrm{mL}^{-1}$, Mediterranean flour moth (Anagasta kuehniella; ALK-Abelló) $4 \mathrm{mg} \cdot \mathrm{mL}^{-1}$, and Granary weevil (Situphilus granarius; ALK-Abelló) $4 \mathrm{mg} \cdot \mathrm{mL}^{-1}$.

\section{Serum specific and total IgE antibodies}

Specific IgE antibodies towards birch, grass, mugwort, horse, dandruff, cat and dog hair, two house dust mites, (Der $P_{1}$, Der $\left.F_{1}\right)$, two storage mites (A. siro, L. destructor), two moulds (A. alternate, A. fumigatus) wheat, rye, oat, barley, mouse, $\alpha$ amylase, maltogenic amylase, hemicellulase, cockroach (Blatella germanica), flour moth (Anagasta kuehniella), granary weevil (Situphilus granarius) were measured using the in vitro

TABLE 1 Characteristics of the baker apprentices (BA) during follow-up

\begin{tabular}{|c|c|c|c|c|c|c|}
\hline & \multicolumn{6}{|c|}{ Follow-up period } \\
\hline & \multicolumn{3}{|c|}{4 months } & \multicolumn{3}{|c|}{20 months } \\
\hline BA $n$ & 114 & 72 & 42 & 87 & 52 & 35 \\
\hline Atopy & $40(35)$ & $29(40)$ & $11(26)$ & $44(51)$ & $31(60)^{*}$ & $13(43)$ \\
\hline Allergy in family & $38(33)$ & $15(21)^{*}$ & $23(55)$ & $25(29)$ & $13(26)$ & $12(33)$ \\
\hline $\lg \mathrm{E}>150 \mathrm{ku} \cdot \mathrm{mL}^{-1 \#}$ & $13(11)$ & $11(15)$ & $2(5)$ & $9(10)$ & $8(16)$ & $1(3)$ \\
\hline Positive SPT for grass & $14(12)$ & $12(17)$ & $2(5)$ & $8(9)$ & $6(12)$ & $2(6)$ \\
\hline BHR" & $8(7)^{+}$ & $3(4)$ & $5(12)$ & $8(9)^{5}$ & $2(4)$ & $6(17)$ \\
\hline Baker in family & $23(20)$ & $15(21)$ & $8(19)$ & $18(21)$ & $10(20)$ & $8(22)$ \\
\hline
\end{tabular}


diagnostic kit, Magic Lite ${ }^{\circledR}$, SQ Allergy. The extracts used were the same as in SPT. Values $\leqslant 1.43 \mathrm{SU} \cdot \mathrm{mL}^{-1}$ were regarded as negative. Serum total $\operatorname{IgE}$ was measured and a value $>150 \mathrm{UI} \cdot \mathrm{mL}^{-1}$ was classified as abnormally high.

\section{Atopy}

Atopy was defined as at least one positive SPT reaction to common inhalant allergens with a wheal diameter $\geqslant 3 \mathrm{~mm}$.

\section{Lung function testing}

Lung function was measured using a dry wedge (VitalographMDI compact ${ }^{\circledR}$; Vitalograph Ltd, Buckingham, England). The spirometer was calibrated before each session. Predicted values for forced expiratory volume in one second (FEV1) and forced vital capacity (FVC) were computed using normal predicted values from European Community for Coal and Steel [21].

\section{Methacholine challenge test}

Bronchial hyperresponsiveness (BHR) was determined using the method of YAN et al. [22] with a Spira Elektro 2® dosimeter (Spira Respiratory Care Center Ltd, Hämeenlinna, Finland) and a maximum cumulated methacholine dose of 1,440 $\mathrm{mg}$. Exclusion criteria for the test were either a predicted FEV1 baseline $\leqslant 70 \%$ or pregnancy. In these cases a $\beta_{2}$-reversibility test was performed. Methacholine test results were expressed either as provocative concentration causing a $20 \%$ fall in FEV1 (PD20) or log dose slope, according to standard methods [23].

\section{Diagnostic criteria}

Respiratory symptoms are symptoms from the upper and lower airways and include asthma-like symptoms and rhinitis.

Asthma was defined if two of the following asthma-like symptoms were present: attacks of chest tightness; episodes of wheezing; spontaneous episodes of cough or cough after exposure to irritants (cold air, dust, exercise), together with a positive methacholine challenge test (at least $20 \%$ decrease in FEV1).

Asthma-like symptoms were defined as any occurrence of the above mentioned symptoms from the lower airways.

Rhinitis was defined if one or more of the classical symptoms of nasal congestion, rhinorrhoea, sneezing or itchy nose were reported and was due to airborne particles. This included at least two of the nasal symptoms on most days [24].

Allergy was defined as a clinical association between being sensitised to an allergen and the development of respiratory symptoms on exposure.

Occupational allergy is defined as a specific allergy to allergens in the occupational setting.

Work-aggravated respiratory symptoms were defined as asthma-like symptoms or rhinitis that became worse in the occupational environment.

\section{Statistical analysis}

Statistical analyses were performed using computer software. Rates were calculated as the number of new cases divided by the person-yrs at risk, during the observation period. The $\mathrm{p}$-values were calculated according to Mantel-Haenszel methodology and $p$-values $<0.05$ were regarded as significant. Cox regression analyses were performed with person-yrs under observation as the dependent variable and of new asthma-like symptoms, hay fever or eye-symptoms, as the event. Explanatory variables were included simultaneously in this model. Each symptom was treated as a separate entity. Atopy was included as an effect modifier.

\section{RESULTS}

From the 114 subjects investigated, 95 remained in the study after 12 months and 87 attended the examination after 20 months. The demographical characteristics of the BA are summarised in table 1 . There were no differences in age and sex distribution during the follow-up period.

The prevalence and incidence rates and the cumulative incidence proportion of symptoms, work-aggravated symptoms and SPT were calculated (fig. 1). The cumulative incidence proportion for rhinitis and asthma-like symptoms and SPT were 41.2, 20.5 and $31.1 \%$, respectively, at the 20 month follow-up (fig. 1). The incidence rate of asthma-like, nose and SPT showed peak values at 4 months. The prevalence of SPTs continued to increase slightly (fig. 1e and f) whereas the prevalence of asthma-like and nose symptoms were almost at the same level during the entire study (fig. 1). The cumulative incidence proportion for nose and asthma-like symptoms showed an increase over time (fig. 1 a-d). The shape of the curve for work aggravated symptoms is paralleling asthma-like symptoms and rhinitis but at a lower level (fig. 1a-d).

The median (range) time for the first symptom to arise from the nose was 237 (180-520) days, from the lower airway was 374 (115-550) days and for new sensitisation by a SPT was 477 (297-644) days. Only one person developed asthma during the follow-up period, according to diagnostic criteria.

The survival ratio (SR) was further analysed in a Coxregression analysis, to control for confounding in the study of risk factors for the development of symptoms (fig. 2). The current authors found a significant $(65 \%)$ increased hazard for asthma-like symptoms among the atopic subjects (SR 0.35, (95\% confidence interval 0.13-0.93); fig. 2 b and c). Females had a significantly $(74 \%)$ higher risk for respiratory symptoms $0.26(0.10-0.69)$ and $54 \%$ risk for work aggravated rhinitis $(0.46$, $0.23-0.92$; fig. $2 \mathrm{a}$ and b). BHR at baseline was associated with the risk of asthma-like symptoms, but not statistically significantly linked.

At the last follow-up visit of the 114 BA, the survival analysis of asthma-like symptoms stratified for SPT and corrected for sex showed 47 had no respiratory symptoms (of which 30 were without symptoms and 17 had symptoms other than the respiratory tract), 31 had rhinitis, 21 had asthma-like symptoms and 15 had both symptoms.

Five BA developed positive SPT to bakery allergens during the study, three developed reactions to wheat and after a 20-month period a further two developed sensitisation as a positive SPT to $\alpha$-amylase. BA with a positive SPT to $\alpha$-amylase had asthmalike symptoms and one had rhinitis symptoms as well. Among the three BA positive to wheat flour only one had positive SPT to grass, two of the three were symptomatic. 


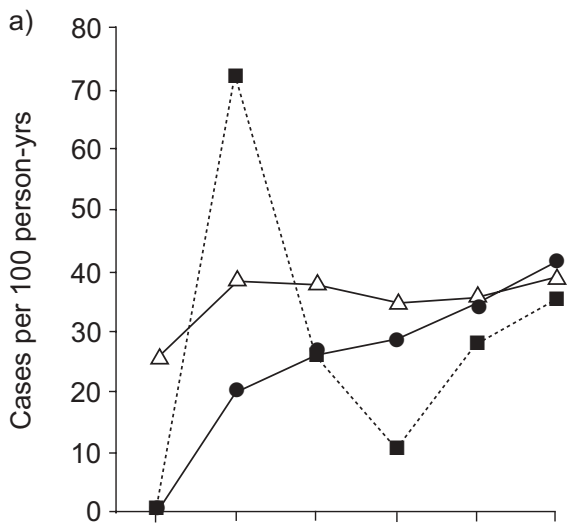

b)

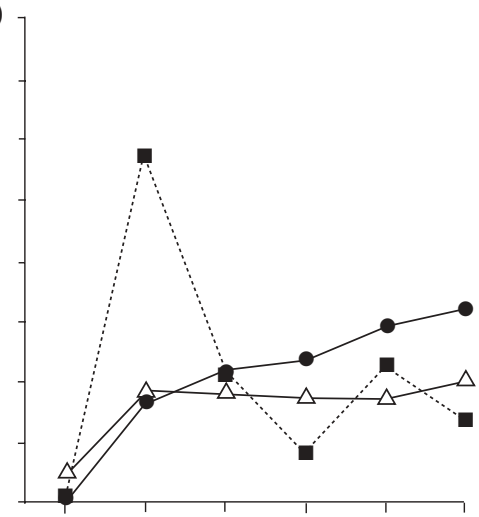

d)

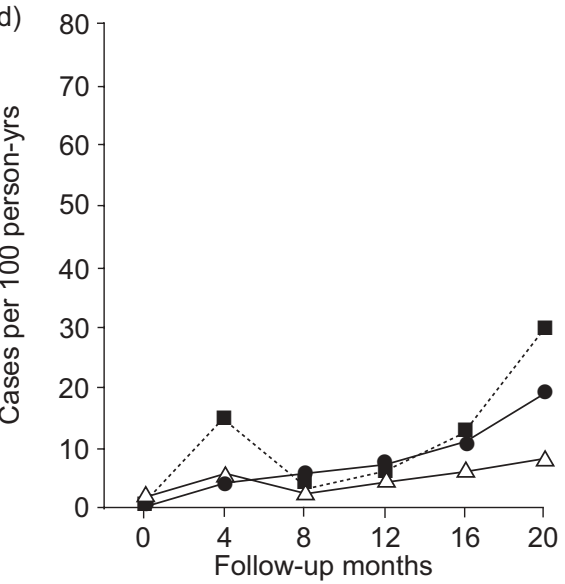

e)

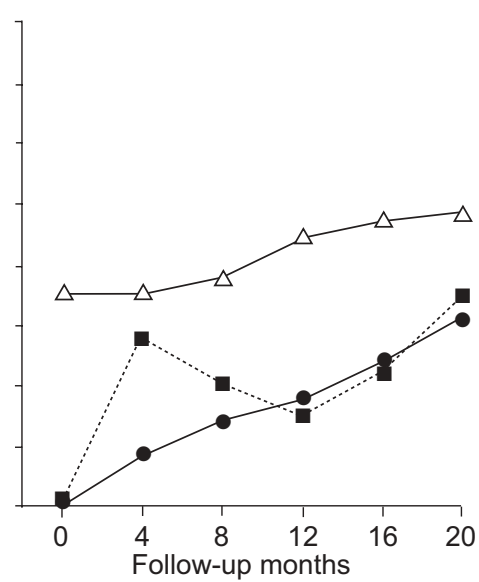

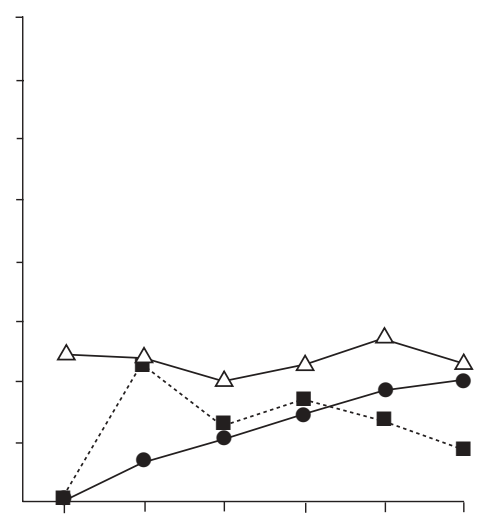

f)

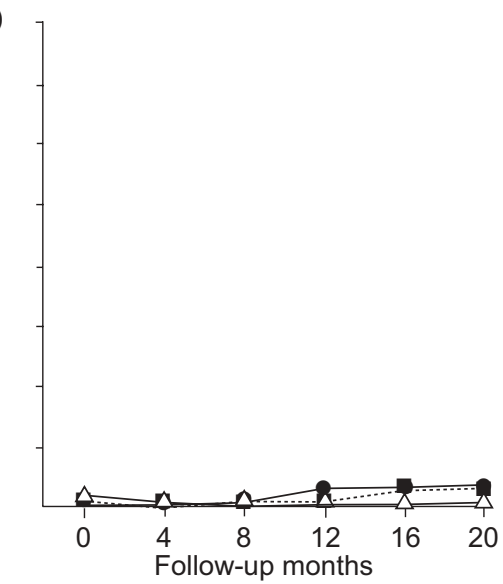

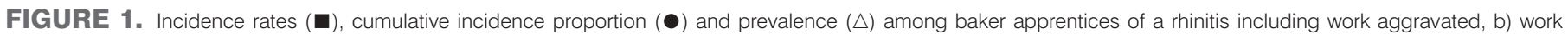

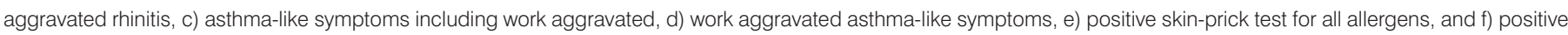
skin-prick test for wheat.

The number with elevated total $\operatorname{IgE}\left(>150 \mathrm{kU} \cdot \mathrm{L}^{-1}\right)$ was much lower than the number with a positive SPT, 16 versus 40 and 10 versus 33 at baseline and the end of follow-up, respectively, and only one BA developed elevated total $\operatorname{IgE}$ during the follow-up.

The degree of bronchial responsiveness was not a risk factor for the occurrence of symptoms either when expressed as PD20 or when expressed as having a slope ratio in the highest quartile. BA who developed asthma-like symptoms had a significant increase in BHR after the 20-month follow-up visit $(p=0.006$, Kruskal Wallis; fig. 3). Smoking was not a risk factor for the occurrence of airway symptoms.

At baseline 65 BA had no respiratory symptoms. Throughout the follow-up period, 35 BA developed at least one symptom, with nose symptoms as the most frequently reported. Six BA developed two symptoms (two had upper airway and skin symptoms, whilst four had upper and lower airway symptoms). Only two BA developed all three symptoms. A total of 30 BA remained without symptoms.

\section{DISCUSSION}

The current study showed that the occurrence of new symptoms from the airways was common among BA.
However, this was not paralleled by sensitisation to occupational allergens, which was rare during the 20 months of follow-up.

The present authors found a high incidence of work-related rhinitis symptoms, 22.1 cases 100 person-yrs ${ }^{-1}$, compared with the recently reported incidences in other groups of bakers and BA varying from 3.6-13.1 cases 100 person-yrs ${ }^{-1}[12,15,16,25,26]$.

The current authors found 10 cases of asthma-like symptoms per 100 person-yrs, of which all were attributed to the work by the BA. This was in the range of 3.6-17.1 cases 100 person-yrs ${ }^{-1}$, observed in recent longitudinal studies of BA $[16,25,27]$. In the study by DE ZOTTI et al. [25] the incidence of respiratory symptoms was only 3.6 per 100 person-yrs. One explanation for this difference could be that the BA in the study by DE ZOTTI et al. [25] were excluded from further follow-up visits when any symptom occurred, contrary to the current study, where BA were followed for each symptom separately. Another possible explanation could be the frequent follow-up visits during the current study compared with previously performed surveys on BA, with a standardised interview on symptoms and clinical tests, hence, diminishing the risk of recall bias.

The incidence rate for asthma-like symptoms, $\sim 4$ months after training, reached a maximum, thereafter it decreased during 

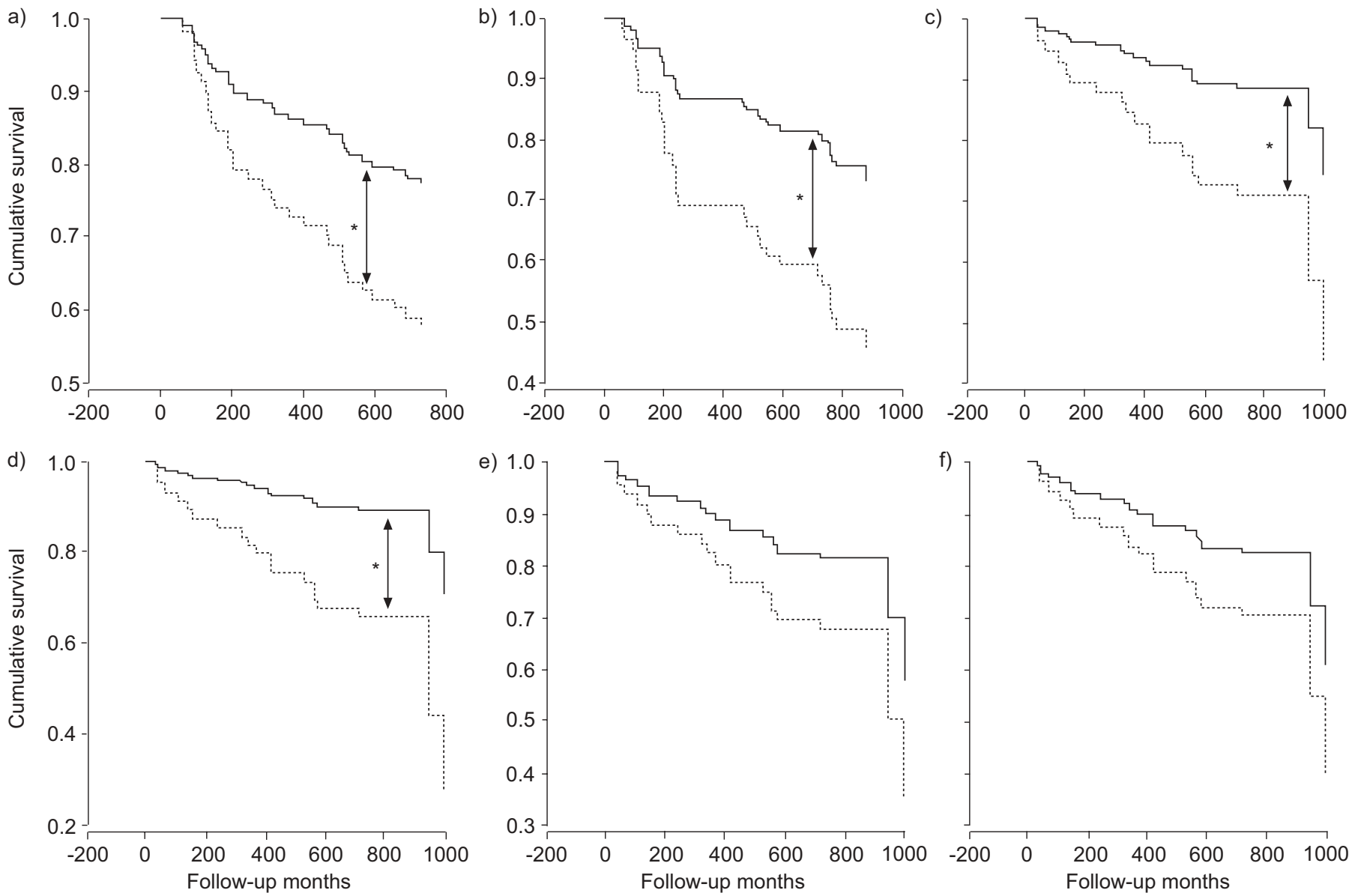

FIGURE 2. Risk factors for the development of respiratory symptoms. a) Survival analysis of rhinitis stratified for sex and corrected skin-prick test (SPT). b) Survival analysis of rhinitis stratified for SPT and corrected for sex. c) Survival analysis of asthma-like symptoms stratified for SPT and corrected for sex. d) Survival analysis of asthmalike symptoms stratified for sex and corrected for SPT. e) Survival analysis of asthma-like symptoms stratified for bronchial hyperresponsiveness and corrected for SPT. f) Survival analysis of asthma-like symptoms stratified for the highest quartile of slope. $\cdots \cdots \cdots \cdot$.... positive ; — : negative. ${ }^{*}$ : $p<0.05$ for Cox-regression analysis.

the next 8-month period, followed by a new increase, although at a lower rate (fig. 1b). The initial peak has been found earlier [25]. This peak could relate to a "harvest phenomenon" i.e. that a large proportion of nonsymptomatic persons in the group develop symptoms immediately after exposure, resulting in a more "resistant" group.

In the multiple regressions analysis, atopy was found as a risk factor for asthma-like symptoms as well as rhinitis, whereas smoking was not classified as a risk factor for the development of symptoms from the airways. The risk of developing airway symptoms was almost doubled among atopics (fig $2 \mathrm{~b}-\mathrm{e}$ ) in accordance with a recent study [16]. Recently, atopy was found to be a risk factor for occupational allergic rhinitis and bronchial asthma $[15,16]$. However, other longitudinal studies have not found this relationship [11, 25]. It has been argued, that atopy should not be included in the statistical model for evaluation of risk factors since it is an intermediate phase between health and asthma, i.e. (healthy $\rightarrow$ atopy $\rightarrow$ asthma) [28]. However, the current authors kept the variable in the model, since no relationship was found in the current study's data.
According to the strict definition given by the current authors only one BA was found to have occupational asthma. However, there is a general problem reaching an agreement on a common definition of asthma in epidemiological studies, which makes comparisons across studies difficult. Hence, a focus on the definition of asthma and rhinitis is needed, as has recently been suggested [29].

BHR at baseline was not a strong risk factor for the development of asthma-like symptoms in accordance with results of GAUTRIN et al. [15]. In that study no significant association between BHR and positive SPT to flour at baseline was found. However, at the 20-month follow-up visit in the present study, a marginally increased risk and an increase in BHR in the BA who developed symptoms during the study was observed. This increase was most likely caused by an inflammatory bronchial reaction as no other explanation, such as bronchial obstruction, was present. Only cases followed until the last follow-up visit were included in the current analysis. Hence the selection bias will tend to underestimate the effect seen in this study. 


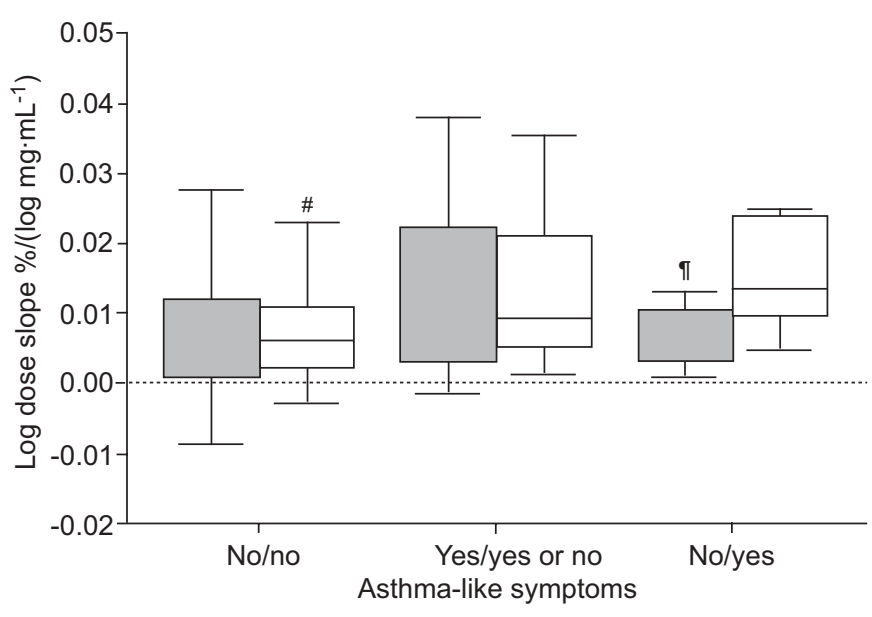

FIGURE 3. Box and whisker plots of the log dose slope for the methacholine provocation at the first $(\square)$ and last examination $(\square)$. No/no: no asthma-like symptoms at inclusion/no asthma-like symptoms at 20-months follow-up; Yes/yes or no: asthma-like symptoms at inclusion/some patients had asthma-like symptoms at 20-months follow-up and some patients' symptoms had disappeared; No/yes: no asthma-like symptoms at inclusion/asthma-like symptoms at 20-months followup. ${ }^{*}: n=30$ outlier; " $n=26$ outlier. Kruskal-Wallis between groups: $p=0.201$ and $\mathrm{p}=0.006$ at the first and second visit, respectively.

The present results underpin the seriousness of the development of respiratory symptoms. Even though the BA with respiratory symptoms did not meet the strict criteria for asthma, an inflammatory condition in the airways causing increase in BHR may have developed concomitantly with the occurrence of symptoms.

Although cross sectional studies among bakers have shown a high prevalence of asthma-like symptoms, [10, 30, 31] the relationship between sensitisation and asthma-like symptoms, so far, seems to be unclear $[8,10,11,13,30,32,33]$. Asthma-like symptoms may progress to asthma [34] but the natural history of this symptom in defined populations has not been studied in great detail.

Based on the literature it was expected that the sensitisation rate to the occupational allergens would be high, as crosssectional studies have established the sensitisation rate between $5-28$ and $2-16 \%$ for wheat flour and $\alpha$-amylase, respectively [35]. Only a few BA became sensitised to occupational allergens, although a substantial proportion of the participants reported respiratory symptoms. This might reflect a tendency to seek lower exposures among atopics, since no increasing prevalence of SPT towards common allergens throughout the follow-up time was observed.

Also longitudinal studies have been equivocal with respect to a relationship between occupational sensitisation and asthmalike symptoms, some studies have found this relationship [16, $25]$, whereas other have been unable to do so [12, 15]. Exposure and sensitisation to occupational allergens is probably not the primary cause of asthma in this group of young adults. Allergy and asthma may actually develop through separate pathways [36]. Atopy but not sensitisation towards occupational allergens was a risk factor for symptoms and could be hypothesised that allergens, apart from occupational allergens or so far uninvestigated allergens, could be responsible. The latter is not a likely explanation, since an extensive range of possible allergens found in bakeries were investigated. However, the current authors' suggestion is contrary to findings in a recent longitudinal study showing that a positive wheat-SPT was a risk factor for the development of workrelated rhino-conjunctivitis [15].

The low sensitisation rate observed in the present study may be caused by a low sensitivity of the SPT extracts and for the specific IgE, as shown previously [37]. However, another explanation is that there is no single route leading from exposure through to sensitisation and to symptoms [16]. The sequences of events are probably more complex and symptoms may arise independently of sensitisation.

The current longitudinal investigation was planned in order to study the allergic march theory, i.e. the sequence of events leading from initial exposure to symptoms and disease. The allergic march theory anticipates a sequence of sensitisation followed by the manifestation of symptoms in the nose as allergic rhinitis that may progress to asthma [38]. Contrary to expectations it was found that asthma-like symptoms and rhinitis appear without a detectable occupational sensitisation, although atopy seemed associated to symptoms. Another recent study of BA also failed to confirm allergic march, as rhinitis occurred before asthma in only $20 \%$ of cases and sensitisation was not always preceding symptoms [16]. This phenomenon is probably not confined to occupational settings, but may implicate the natural history of allergic disease in general. This may also be the reason why allergy cannot explain and account for asthma as a disease manifestation, even in atopic individuals.

Longitudinal studies are time consuming and difficult to perform especially when young adults are participating and in the current study the initial drop-out rate of $53.4 \%$ was almost of the same magnitude as in the previous studies of DE ZOTTI et al. [25] (62.4\%), Gautrin [15] (45.2\%) and WALUSIAK et al. [16] $(37.7 \%)$. The greatest drop-out rate was seen in the study of newly employed bakery and flour mill workers in the UK, where $80 \%$ left the study before the end of the 3-yr follow-up period [11]. Hence, it is a general problem in this occupational area, especially if the latency period is lengthy [39].

Analyses of the drop-out rates of BA in longitudinal studies are infrequently reported. WALUSIAK et al. [16] only found healthbased selection. The BA in the present study never ascribed leaving the profession to a health problem except for ergonomic problems and the reasons for participants to leave the study was mainly due to factors related to social problems with night-work and employment. However, in an interview 4 months previous to the BA dropping out of the study, 30\% reported respiratory symptoms.

The present study found that the occurrence of new respiratory symptoms in BA was high and associated to atopy, being female and increased BHR, but mechanisms other than type 1 mediated allergy seemed to be responsible for this phenomenon. Future research should be directed to identify the responsible mechanism behind this phenomenon, since this is probably of general relevance for the study of asthma and 
allergy. The design must include a follow-up style investigation and preferably it should be in previously unexposed workers, e.g. baker apprentices or the new expanding group of shop assistants engaged in the finalising of pre-baked bread, as in the study by CULLINAN et al. [11]. The follow-up should be directed towards the important events occurring at the beginning of employment as shown in the current study. The initial follow-up could then be changed to a more extensive scheme during the following years, allowing enough time (>20 months) for occupational allergies to develop. There are many hurdles to be overcome in longitudinal studies, such as participants dropping out and high costs. However, only with this type of study design will it be possible to learn more about the interaction between all the symptoms and clinical findings comprising of baker's allergy, asthma and rhinitis and their temporal sequence.

\section{REFERENCES}

1 Blanc PD, Toren K. How much adult asthma can be attributed to occupational factors? Am J Med 1999; 107: 580-587.

2 McDonald JC, Keynes HL, Meredith SK. Reported incidence of occupational asthma in the United Kingdom, 1989-97. Occup Environ Med 2000; 57: 823-829.

3 Karjalainen A, Kurppa K, Virtanen S, Keskinen H, Nordman H. Incidence of occupational asthma by occupation and industry in Finland. Am J Ind Med 2000; 37: 451-458.

4 Nordman H. Incidens af yrkesastma. In: Tornling G, ed. Yrkesastma. Glaxo Wellcome AB, Mölndal, Sweden, 1997; pp.15-23.

5 Baur X. Baker's asthma: causes and prevention. Int Arch Occup Environ Health 1999; 72: 292-296.

6 Pedersen L. Allergi og allergiske lidelser hos bagere. Occupational Foundation, Denmark, 1996.

7 Baldo BA, Wrigley CW. IgE antibodies to wheat flour components. Studies with sera from subjects with baker's asthma or coeliac condition. Clin Allergy 1978; 8: 109-1024.

8 Houba R, Heederik DJ, Doekes G, van Run PE. Exposuresensitization relationship for alpha-amylase allergens in the baking industry. Am J Respir Crit Care Med 1996; 154: 130-136.

9 Baur X, Posch A. Characterized allergens causing bakers' asthma. Allergy 1998; 53: 562-566.

10 Jeffrey P, Griffin P, Gibson M, Curran AD. Small bakeries-a cross-sectional study of respiratory symptoms, sensitization and dust exposure. Occup Med 1999; 49: 237-241.

11 Cullinan P, Lowson D, Nieuwenhuijsen MJ, et al. Work related symptoms, sensitisation, and estimated exposure in workers not previously exposed to flour. Occup Environ Med 1994; 51: 579-583.

12 Cullinan P, Cook A, Nieuwenhuijsen MJ, et al. Allergen and dust exposure as determinants of work-related symptoms and sensitization in a cohort of flour-exposed workers; a case-control analysis. Ann Occup Hyg 2001; 45 : 97-103.

13 Smith TA, Smith PW. Respiratory symptoms and sensitization in bread and cake bakers. Occup Med 1998; 48: 321-328.

14 Smith TA, Parker G, Hussain T. Respiratory symptoms and wheat flour exposure: a study of flour millers. Occup Med 2000; 50: 25-29.
15 Gautrin D, Ghezzo H, Infante-Rivard C, Malo JL. Incidence and host determinants of work-related rhinoconjunctivitis in apprentice pastry-makers. Allergy 2002; 57: 913-918.

16 Walusiak J, Hanke W, Gorski P, Palczynski C. Respiratory allergy in apprentice bakers: do occupational allergies follow the allergic march? Allergy 2004; 59: 442-450.

17 Skjold T, Nielsen SC, Hoffmann HJ, Adolf K, Dahl R, Sigsgaard T. Allergy in bakers' apprentices and factors associated to non-participation in a cohort study of allergic sensitization. Int Arch Occup Environ Health 2007; 80: 458-464.

18 Burney PG, Luczynska C, Chinn S, Jarvis D. The European Community Respiratory Health Survey. Eur Respir J 1994; 7: 954-960.

19 The European Community Respiratory Health Survey (ECRHS). Questionnaires and Protocols ECRHS main questionnaire 11. www.ecrhs.org/quests.htm Date last accessed: September 25, 2007. Date last updated December, 14, 2007.

20 Dreborg S. Skin prick test. Allergy 1985; 40: Suppl. 4, 55-65.

21 Quanjer PH, Tammeling GJ, Cotes JE, Pedersen OF, Peslin R, Yernault JC. Lung volumes and forced ventilatory flows. Report Working Party Standardization of Lung Function Tests, European Community for Steel and Coal. Official Statement of the European Respiratory Society. Eur Respir J 1993; 6: Suppl. 16, 5-40.

22 Yan K, Salome C, Woolcock AJ. Rapid method for measurement of bronchial responsiveness. Thorax 1983; 38: 760-765.

23 Miller MR, Sigsgaard T, Omland O, Pedersen OF. Time domain and flow indices of bronchial hyperresponsiveness: association with asthma symptoms, atopy and smoking. Eur Respir J 2002; 20: 86-91.

24 International Consensus Report on the diagnosis and management of rhinitis, International Rhinitis Management Working Group. Allergy 1994; 49: 1-34.

25 De Zotti R, Bovenzi M. Prospective study of work related respiratory symptoms in trainee bakers. Occup Environ Med 2000; 57: 58-61.

26 Smith TA. Preventing baker's asthma: an alternative strategy. Occup Med 2004; 54: 21-27.

27 Gautrin D, Ghezzo H, Infante-Rivard C, Malo JL. Incidence and determinants of IgE-mediated sensitization in apprentices. A prospective study. Am J Respir Crit Care Med 2000; 162: 1222-1228.

28 Koskela HO, Iivanainen KK, Remes ST, Pekkanen J. Petand pollen-induced upper airway symptoms in farmers and in nonfarmers. Eur Respir J 2003; 22: 135-140.

29 Pekkanen J, Sunyer J, Anto JM, Burney P. Operational definitions of asthma in studies on its aetiology. Eur Respir J 2005; 26: 28-35.

30 Baur X, Degens PO, Sander I. Baker's asthma: still among the most frequent occupational respiratory disorders. J Allergy Clin Immunol 1998; 102: 984-997.

31 Droste J, Myny K, Van Sprundel M, et al. Allergic sensitization, symptoms, and lung function among bakery workers as compared with a nonexposed work population. J Occup Environ Med 2003; 45: 648-655.

32 Musk AW, Venables KM, Crook B, et al. Respiratory symptoms, lung function, and sensitisation to flour in a British bakery. Br J Ind Med 1989; 46: 636-642.

33 Houba R. Occupational respiratory allergy in bakery workers. Relationships with wheat and fungal $\alpha$-amylase 
aeroallergen exposure. PhD. Wageningen Agricultural University, Wageningen, the Netherlands, 1996.

34 Rytilä P, Ghaly L, Varghese S, et al. Treatment with inhaled steroids in patients with symptoms suggestive of asthma but with normal lung function. Eur Respir J 2008; Epub ahead of print [PMID: 18508828].

35 Houba R, Doekes G, Heederik D. Occupational respiratory allergy in bakery workers: a review of the literature. Am J Ind Med 1998; 34: 529-546.

36 Lau S, Illi S, Sommerfeld C, et al. Early exposure to housedust mite and cat allergens and development of childhood asthma: a cohort study. Multicentre Allergy Study Group. Lancet 2000; 356: 1392-1397.

37 Sander I, Merget R, Degens PO, Goldscheid N, Bruning T, Raulf-Heimsoth M. Comparison of wheat and rye flour skin prick test solutions for diagnosis of baker's asthma. Allergy 2004; 59: 95-98.

38 Wahn U. What drives the allergic march? Allergy 2000; 55 591-599.

39 Herxheimer $H$. The skin sensitivity to flour of baker's apprentices. A final report of a long term investigation. Acta Allergol 1973; 28: 42-49. 